\title{
Design and Analysis of MEMS based Composite Piezoelectric Ultrasonic Transducer
}

\author{
T. Satyanarayana ${ }^{1}$, G. Srinivas ${ }^{2}$, M V V K Srinivas $\operatorname{Prasad}^{2}$, Y. Srinivas ${ }^{3}$, B. Sudheer ${ }^{4}$, K. Srinivasa Rao ${ }^{1, *}$ \\ ${ }^{1}$ Department of Electronics \& Instrumentation Engineering, Lakireddy Balireddy College of En gin eering, Mylavaram, 521 230, Andhra \\ Pradesh, India \\ ${ }^{2}$ Department of Phy sics, KL University, Vadeswaram, Guntur District, Andhra Pradesh, India \\ ${ }^{3}$ Department of Computer Science, GITAM University, Hy derabad, India \\ ${ }^{4}$ Department of Mechanical En gin eering, Lakireddy Balireddy College of En gineering, Mylavaram, 521 230, Andhra Pradesh, India
}

\begin{abstract}
With the rapid growth of technology, micro scale devices are playing a dominant role in mechanical and optoelectronic devices. Characteristics like miniaturization, multiplicity and microelectronics help these devices to sense, control and actuate on micro scale with effects on macro scale. Micro devices like composite transducers are widely used in medical, industrial and space applications because they are relatively simple and easy to interface with other devices and also provide better resolution and easy installation. The present work reports the design and simulation of composite piezoelectric ultrasonic transducer, where susceptance was computed by applying AC potential for various piezoceramic materials i.e., Nepec 6, Quartz, Pzt-8. In this, an eigen frequency analysis is followed by a frequency response analys is to calculate the input admittance as a function of the excitation frequency. To make this design, COMSOL Multiphysics software is used. The transducer designed with PZT-8 has exhibited better sensitivity than others. These transducers are widely used in non-destructive testing (NDT), weld ing, machining, medical imaging etc.
\end{abstract}

Keywords MEMS Composite Transducer, Susceptance Analysis, COMSOL Multiphysics 4.2a

\section{Introduction}

Control is more important than information processing; it implies that there is a direct interaction with the physical world. Control systems include sensors and actuators, which help us to ensure that automation systems can manage activities and environments in desired ways. In this context MEMS has been identified as one of the most promising technologies for the 21st Century and has the potential to revolutionize both industrial and consumer products by combining silicon-based microelectronics with micromachining technology[1-7]. They usually consist of a central unit that processes data, the microprocessor and several components that interact with the outside such as micro sensors[8-9]. This techniques use mic ro system-based devices that have the potential to dramatically effect of all of our lives and the way we live by providing the min iaturized devices. A micro- electro mechanical system (MEMS) is a process technology used to create tiny integrated devices or systems that combine mechanical and electrical components. They are fabricated us ing integrated circuit (IC) batch processing techniques and can range in size from a few

* Corresponding author:

srinivasakarumuri@gmail.com (K. Srinivasa Rao)

Published online at http://journal.sapub.org/eee

Copyright (C) 2012 Scientific \& Academic Publishing. All Rights Reserved micro metres to millimetres. These devices (or systems) have the ability to sense, control and actuate on the micro scale, and generate effects on the macro scale. In this context, there has been increasing demand for ultrasonic transducers due to its potential applications, including non-destructive testing (NDT), welding machining, cleaning, underwater communication, navigation, map building, ultrasonic surgery, etc. Among different types of transducers viz., sonic, ultrasonic and mega sonic, ultrasonic transducers usually work at a frequency range from $20 \mathrm{kHz}$ to $200 \mathrm{kHz}[10]$. Features like high acoustic efficiency, mechanical fle xibility, low mechanical Q, low cross talk and low acoustic impedance made these transducers to be used in wide range of applications. Generally this sensor works by emitting a short burst of $40 \mathrm{kHz}$ ultrasonic sound from a piezoelectric transducer. Ultrasonic transducer playsan important role in both generating and receiving ultrasound in an ultrasonic measurement system. In general, they are complex electromechanical devices that are difficult to characterize and design. The sensitivity and resolution of the device entirely depend upon the piezocomposite materials being used. There are high resolutions producing devices in the market which are built by using lead metaniobate piezoceramic or piezoelectric polymers. But these are showing low sensitivity as most of the acoustic energy is absorbed in the backing and materials efficiency is lowered. As these transducers involve both the combination of 
electrical and mechanical components, it is difficult to for us to analyse them. Whereas a Piezoelectric ceramic and a passive polymer are combined to get a piezo composite, which helps us to design the transducer that is producing better results than the conventional piezoelectric devices[11]

Thus, the present study is mainly focused on design of composite piezoelectric ultrasonic transducer with three different piezoelectric materials and computation of susceptance as a function of excitation frequency for the proposed structure.

\section{Theoretical Background}

To generate and measure the ultrasonic pulses, the composite transducer is working based on the phenomenon of piezoelectric effect. Piezoelectric ceramics and single crystal materials are the two main materials which are used for generation of piezoelectric effect in the transducers. Lead zirconate titanate, also called PZT is the most common piezoelectric ceramic which is used today along with other materials like sodium tungstates, lithium tantalite, lead titanate, zinc oxide, barium titanate and barium strontium titanate. On the other hand single crystal materials like magnesium niobate-lead titanate are also used in manufacturing of these transducers along with gallium phosphate, quartz and tourmaline. These crystals provide the fle xibility in designing, so that they can be made into various shapes to achieve different vibration modes, which help the transducer in operating fro $\mathrm{m}$ low $\mathrm{kHz}$ range up to the $\mathrm{MHz}$ range. The piezoelectric effects generated when mechanical stress is applied between surfaces of a solid dielectric. Conversely when a voltage is applied across certain surfaces of a solid then it undergoes a mechanical distortion and exhibits the piezoelectric effect. As piezoelectricity is the combined effect of the electrical behaviour of the material i.e.,

$$
\mathrm{D}=\mathrm{CE}
$$

Where $\mathrm{D}$ is the electric charge density displacement (electric displacement), $\varepsilon$ is permittiv ity and $\mathrm{E}$ is electric field strength. Linear elasticity equations are coupled with electrostatic charge equations by means of electric constants to obtain a reasonable model of this interaction. So the stress charge form of equations is as follows

$$
\begin{aligned}
& \mathrm{T}=\mathrm{C}_{\mathrm{E}} \cdot \mathrm{S}-\mathrm{e}^{\mathrm{t}} \cdot \mathrm{E} \\
& \mathrm{D}=\mathrm{e} \cdot \mathrm{S}+\mathrm{C}_{\mathrm{S}} \cdot \mathrm{E}
\end{aligned}
$$

Where $\mathrm{S}$ is the stress, et is the permittivity at constant strain, $T$ is the stress. When stress is applied these crystals bends in different ways at different frequencies, but they will be resonating within narrow frequency ranges. Some of the transducers which use the piezoelectric materials are phonograph cartridges, microphones, and strain gauges that produce an electrical output from a mechanical input. But a mechanical output from an electrical input can be observed in earphones and ultrasonic transmitters. Generally electrostatic transducers have very high initial cost and very low system resistance but whereas piezo transducers are less expensive thereby making its construction best suited for harsh environments.

\section{Use of Comsol Multiphysics}

The software package selected to model and simulate the MEMS composite ultrasonic transducer was COMSOL Multiphysics Version 4.2 a.It is a powerful interactive environment for modelling and Multiphysics were selected because there was previous experience and expertise regarding its use as well as confidence in its capabilities. This provides the flexibility of selecting the required vertex for applying the inputs by rotating the geometry in the work plane. This consists of material library where we can find different material branches like MEMS, semiconductors $(\mathrm{Ga}$ $\mathrm{As}, \mathrm{Ge}, \mathrm{C}[100]$ etc), insulators(A12 O3,Si2 O3), polymers and piezoelectric (Barium sodium niobate, Lithium niobate, Lead zirconate titanate etc) can be selected.

\section{Design Process}

The design of composite piezoelectric transducer starts from defining parameters for the required geometry, selection of necessary material and addition of physical interfaces. For modelling, certain instructions must be followed. First, selection of piezo electric devices (pzd) and then eigenfrequency analysis was chosen. For required shape, first circle with radius $27.5 \mathrm{e}-3 \mathrm{~m}$. Later, bezier polygon is chosen and its segments are located in the control point sub section by adding the value of $\mathrm{x}$ in row 2 for about 0.03 in the add linear button. Now this structure is rotated for about 10 degrees and converted to solid. To reduce memory requirements, we use the structural symmetry by cutting along its mid plane which is perpendicular to central axis. After cutting the geometry, now by locating the points from the work plane, the final 3-D model can be obtained as shown in Fig. 1. Variables must be defined for the susceptance so the compensating factors, symmetry and degree of wedge is taken into consideration, from which mesh can be generated as shown in Fig. 2.

The composite piezoelectric ultrasonic device has a cylindrical geometry. This model consists of a piezocera mic (NEPEC 6)and two Langevin type transducers in which a disk is sandwiched between a pair of aluminium disks by means of adhesive (ARALDITE) i.e., the layers are organized as follows aluminium layer-adhesive layer-piezoceramic layer-adhesive layer- aluminium layer. During the modelling of the geometry, domains must be selected so that the required material can be inserted in the proper area and they are as follows. 


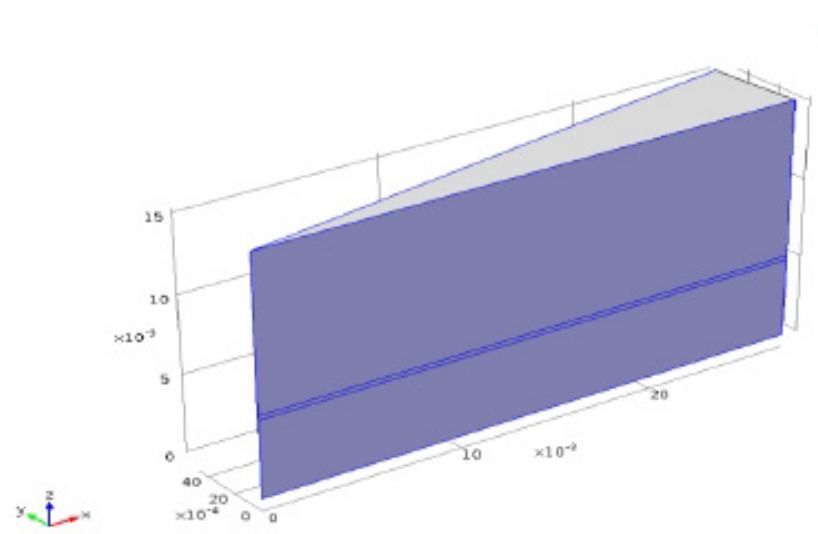

Figure 1. 3-Dimensional view of model

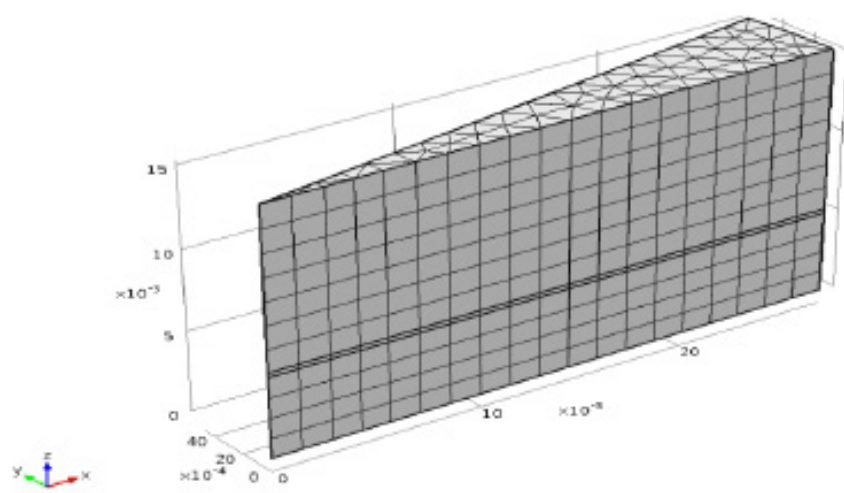

Figure 2. Generating mesh for model

Table 1. Physical properties of material used

\begin{tabular}{|c|c|c|c|c|c|c|}
\hline S. No. & Property & Symbol & Variable & Nepec 6 & Adhesive & Aluminum \\
\hline 1 & $\begin{array}{c}\text { Young's modulus } \\
\left(\mathrm{N} / \mathrm{m}^{2}\right)\end{array}$ & $\mathrm{E}$ & $\mathrm{E}$ & $\begin{array}{c}\mathrm{e}=\{15.7-6.1-6.1 \\
0\}\left(\mathrm{C}^{2} \mathrm{~m}^{2}\right.\end{array}$ & $1 \mathrm{xe}^{10}$ & $7.03 \mathrm{x}^{10}$ \\
\hline 2 & Poisson's ratio & $\sigma$ & $\mathrm{nu}$ & 0.32 & 0.38 & 0.345 \\
\hline 3 & Densit3y $(\mathrm{kg} / \mathrm{m})$ & $\rho$ & rho & 7730 & 1700 & 2690 \\
\hline
\end{tabular}

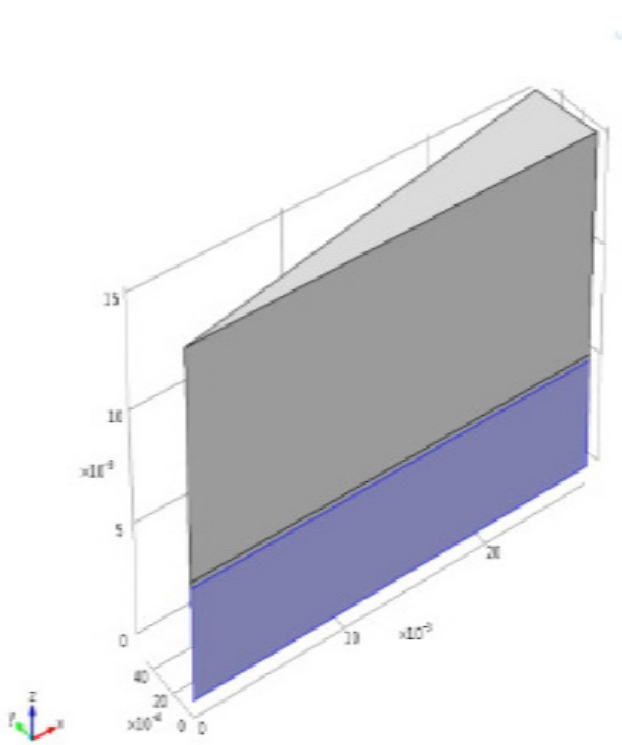

Figure 3. PZT- 8 in domain 1

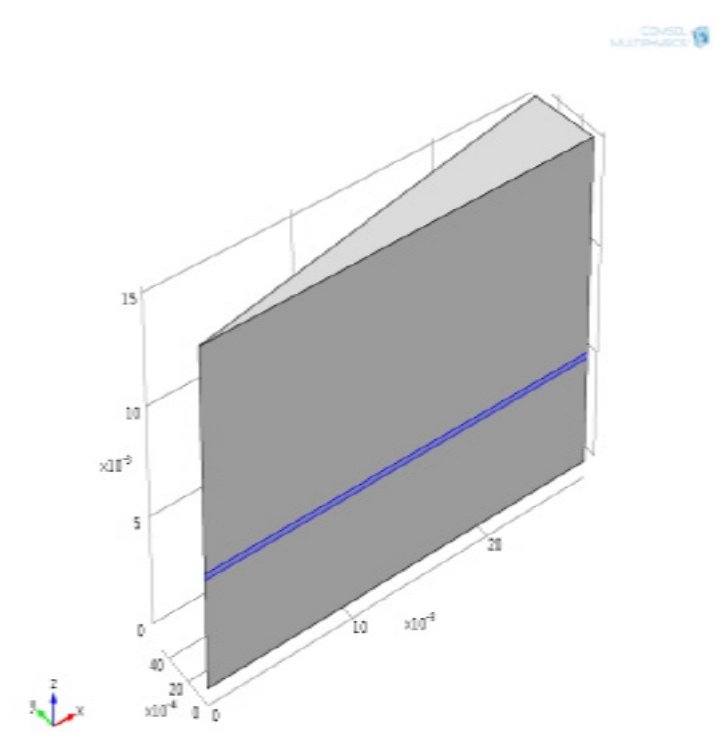

Figure 4. Adhesive in domain 2 


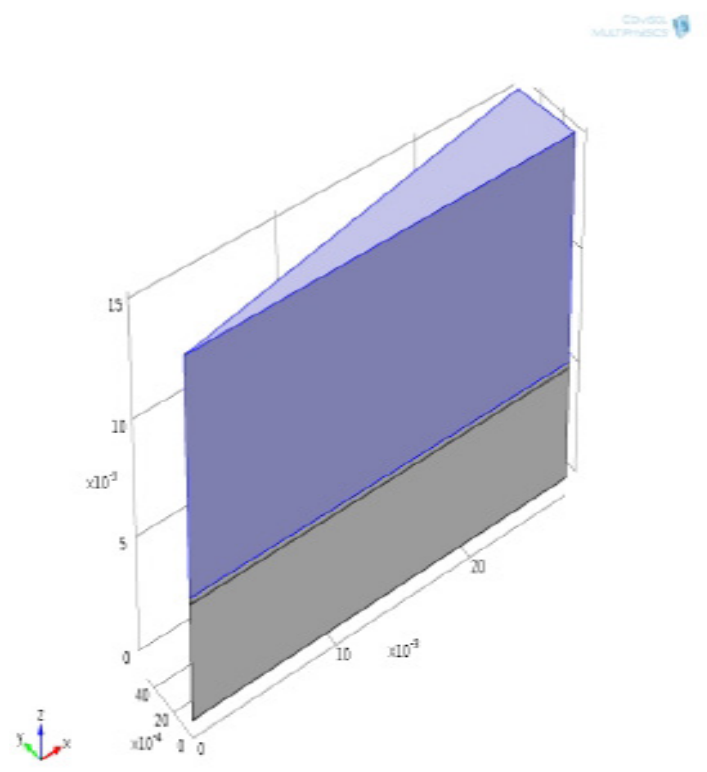

Figure 5. Aluminium in domain 3

This type of construction is used for sonar transducers and is of practical importance because it provides design flexibility by choosing material combinations and dimensions[12]. One of the piezoceramic materials, lead zirconate titanate is most popular choice for medical ultrasonic transducer. This offer high electromechanical coupling a wide selection of dielectric constants which made pzt-8 prominent in selection during the construction of med ical transducers. The material constants used during the design of transducer are tabulated in Table 1.

\subsection{Input Parameters}

Calculating the susceptance for the geometry requires selection of the boundary conditions for the terminal, ground and symmetry position so that the input parameters can be applied. Here as we are modelling only for the upper part of the transducer, this condition lead to the application of the potential for about half of the total peak value i.e., 0.5 volts.

Electrical terminal is selected in boundary 6 so that the voltage can be applied to it form terminal type. Where the ground is selected to boundary 3 from electrical boundary conditions. The condition for satisfying the symmetry is made by selecting the boundaries in the model from 1-5, 7, and 8.The expression for these conditions are given by equations,

1). Terminal $\int_{2 \Omega} \rho_{s} d_{s}=Q_{0}$.

2). Ground $V=0$.

3). Symmetry n.u $=0$.

Linear elastic material model is used here for which equation is given by $\mathrm{C}=\mathrm{C}(\mathrm{E}, \mathrm{V})$, in which $\mathrm{E}$ represents young's modulus and $\mathrm{V}$ for Poisson's ratio.
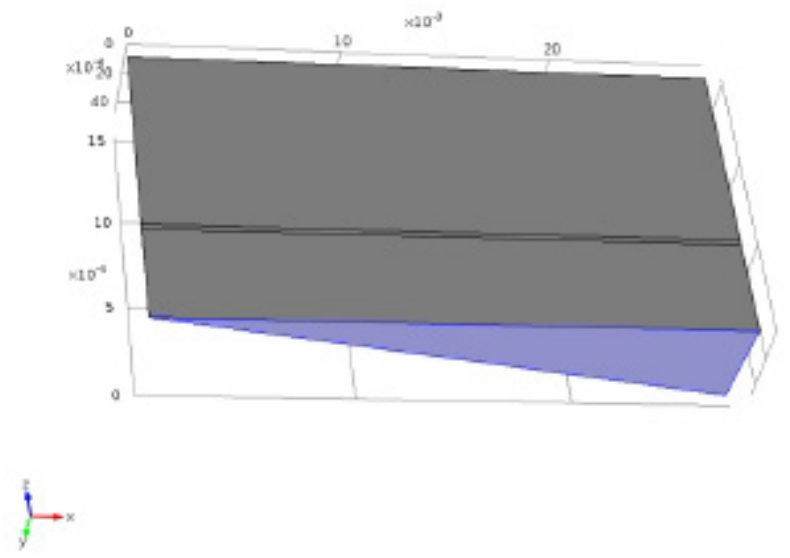

Figure 6. Boundary for ground

\section{Simulation}

Simulation comprises of two phases, where in first one lowest eigen modes are calculated by replacing the expression of displacement field and the other one involves the application of the frequency swept. Deformations are observed after the expression is replaced to susceptance. Since we applied AC potential between the electrical terminals on both sides of the electrode surface, the imaginary part of the admittance i.e., susceptance is calculated. This can be computed by knowing the ratio of total current applied and voltage supplied for the given structure. Where the maximum allowed potential is one volt peak for the first four lowest eigen frequency.

\section{Results and Discussion}

Using software, two kinds of studies has been explored i.e., study 1 for calculation of the lowest eigen modes, Whereas the study 2 corresponds to the frequency domain case in which frequency swept is noted down for the first four eigen frequencies. The range of the frequency is given form $20 \mathrm{e}^{3}$ to $106 \mathrm{e}^{3}$ and for a step about $2 \mathrm{e}^{3}$ deformation is observed by plotting on the material. Now the displacement field, $\mathrm{Z}$ component is selected form the solid mechanics of piezoelectric devices by replacing the expression of surface 1. Eigen modes and slices of deformations are observed by plotting the surface 1 for three different materials, which are shown in Figure 7 and 8 . Total displacement can be observed for the model, after the application of the frequency swept. Later slices are formed for the model which helps in analysing the internal deformation. 1Dimensional graph is obtained by replacing the expression to susceptance for the vertex one, which shows the relation between the susceptance and frequency. 
:e: Displacement field, $Z$ component $\langle m\rangle$ Surtace Detormation: Displacement tield

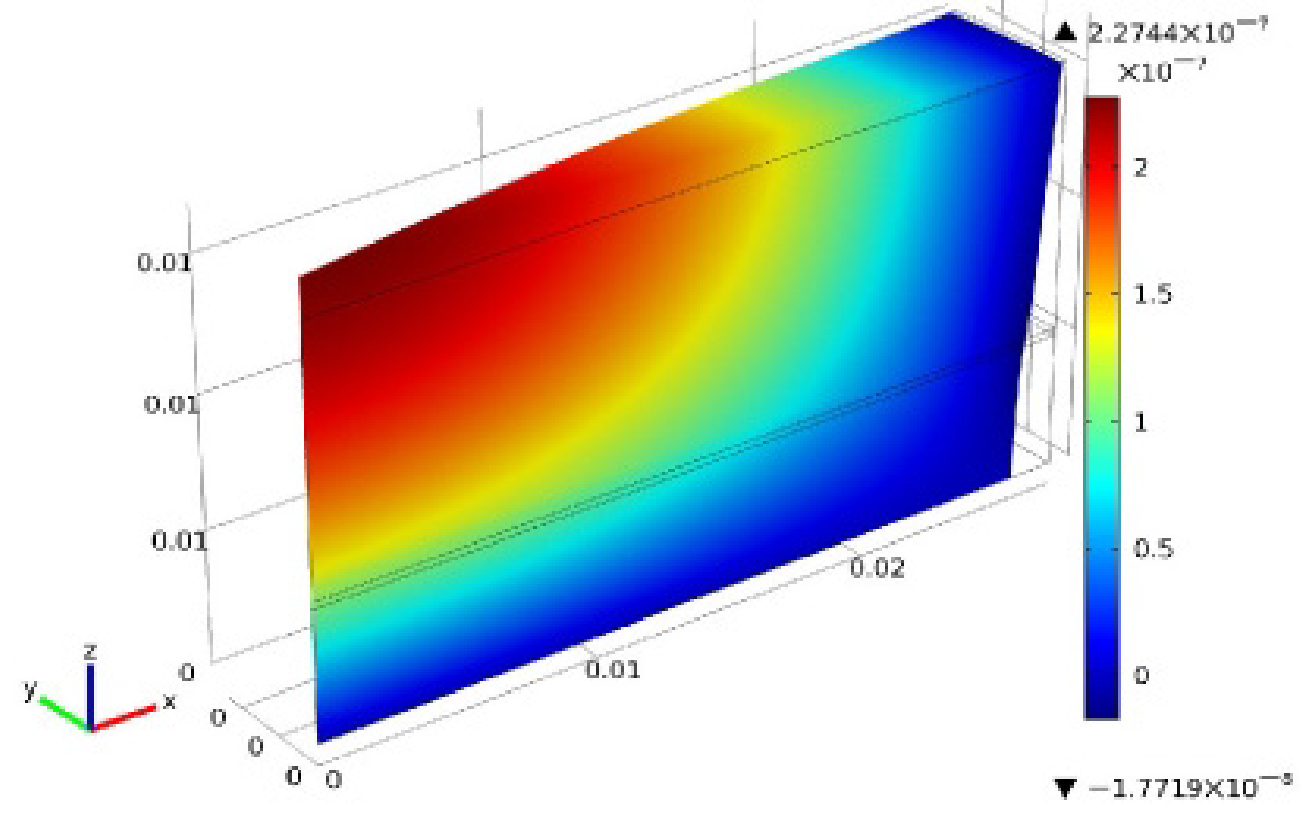

a) Resul ts obtained when Nepec 6 mate rial is used

Eigenfrequency=66360. 867057

Surface: Displacement field, $Z$ component Iml Surface Deformabon: Cisplacement field
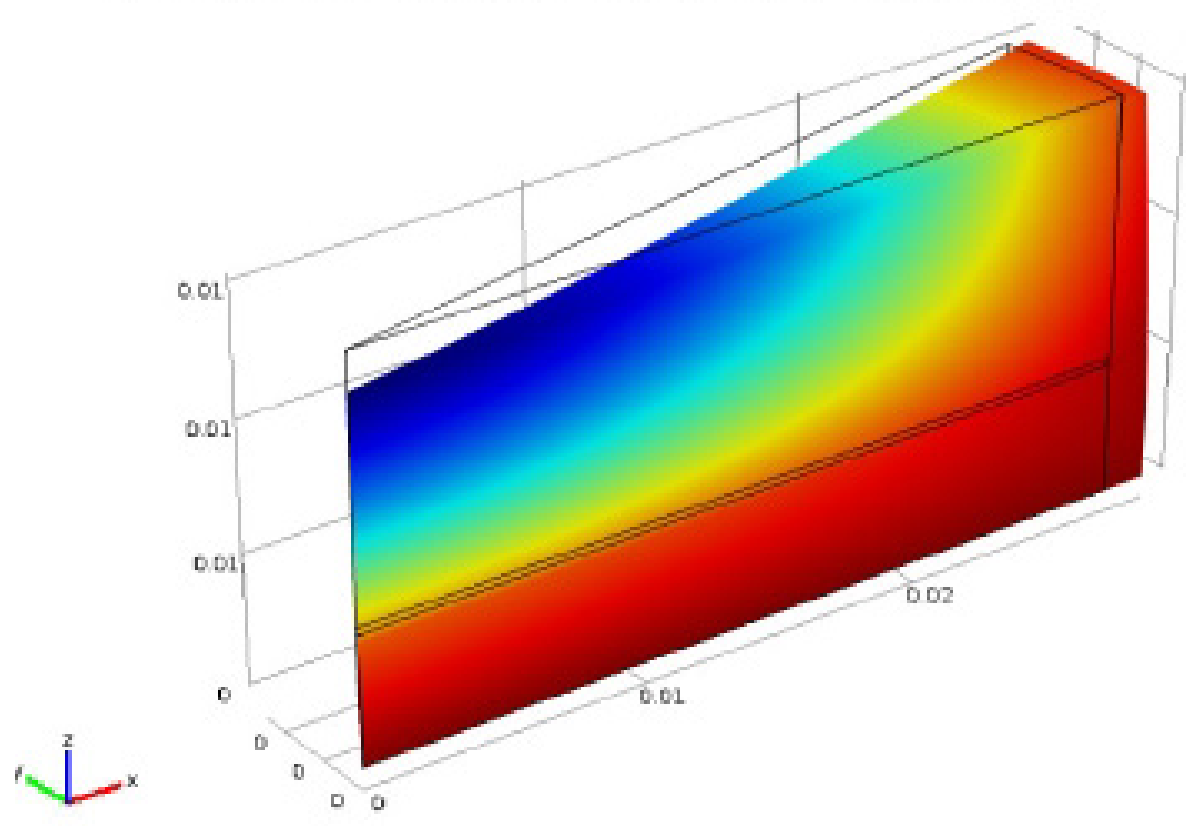

4 $5.066 \times 10^{-10}$

$\times 10^{-8}$

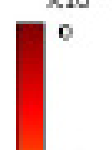

$-1$

7 $-5.2500 \times 10^{-8}$

b) Results obtained when Quartz mate rial is used 


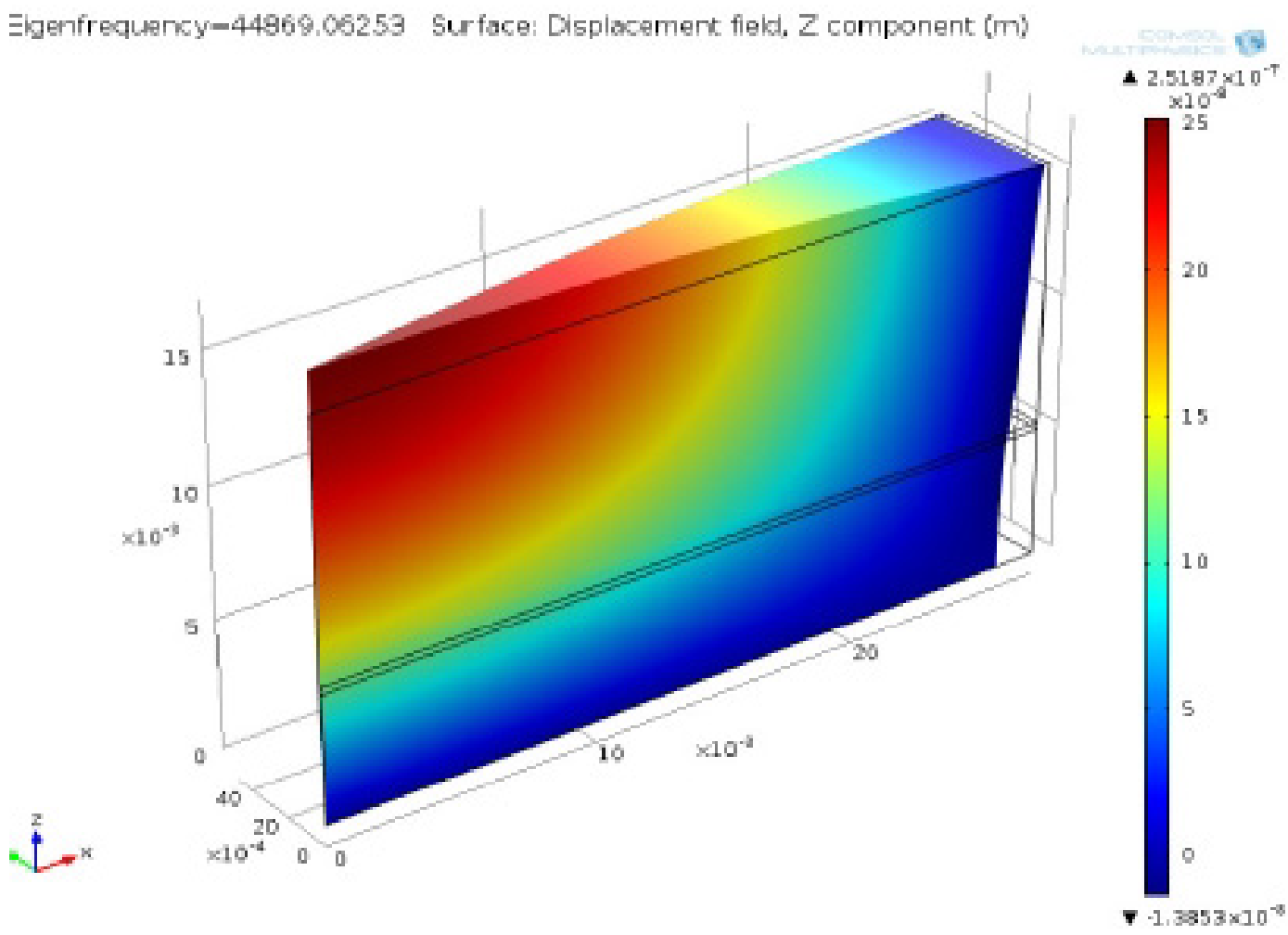

c) Results obtaine d when PZT - 8 material is use d

Figure 7. Lowest vibration eigen mode of the transducer (3-D plot group 1)

Eigenfrequency-43396.964356 Slice: Total displacement (m)

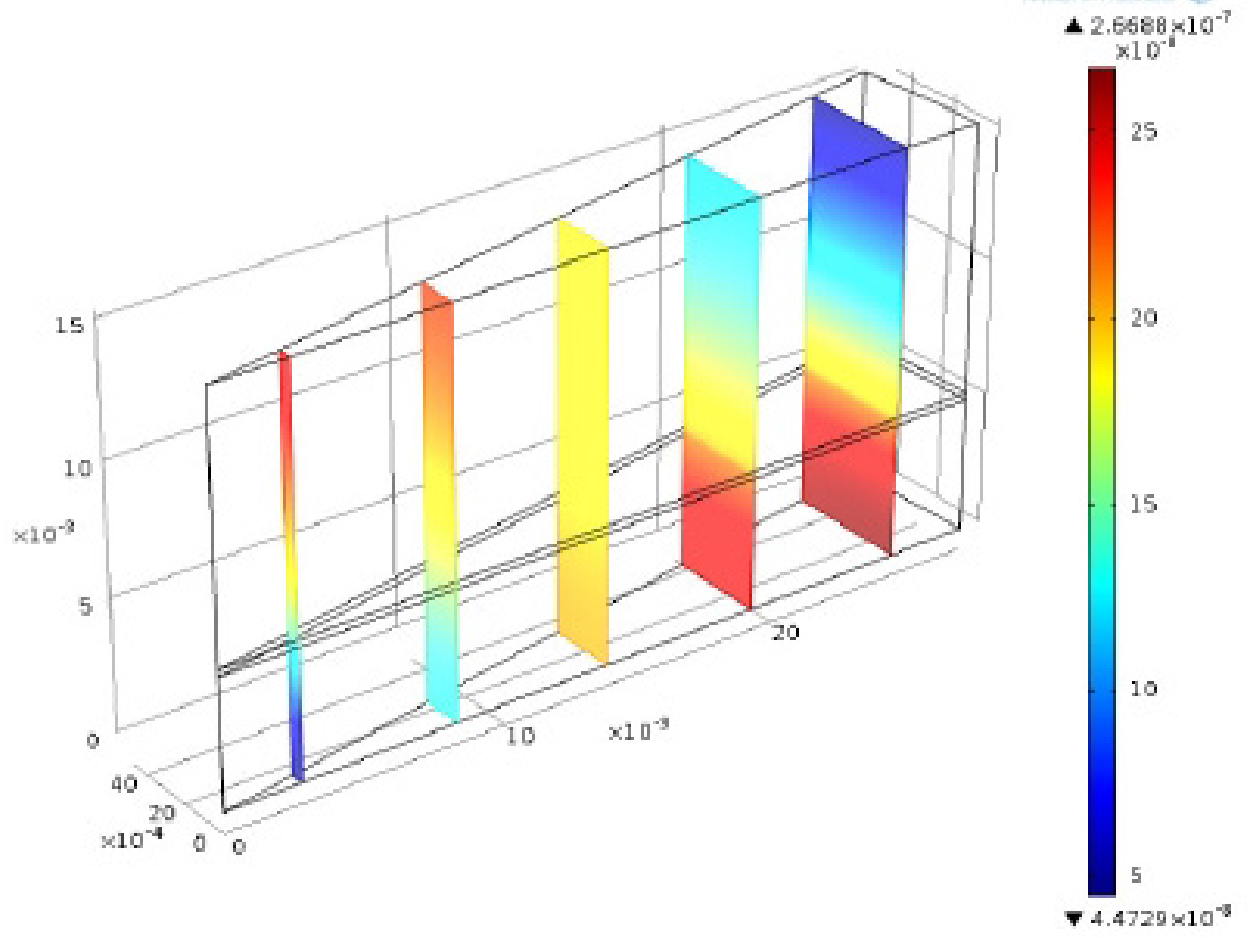

a) Resul ts obtained when Nepec 6 mate rial is used 

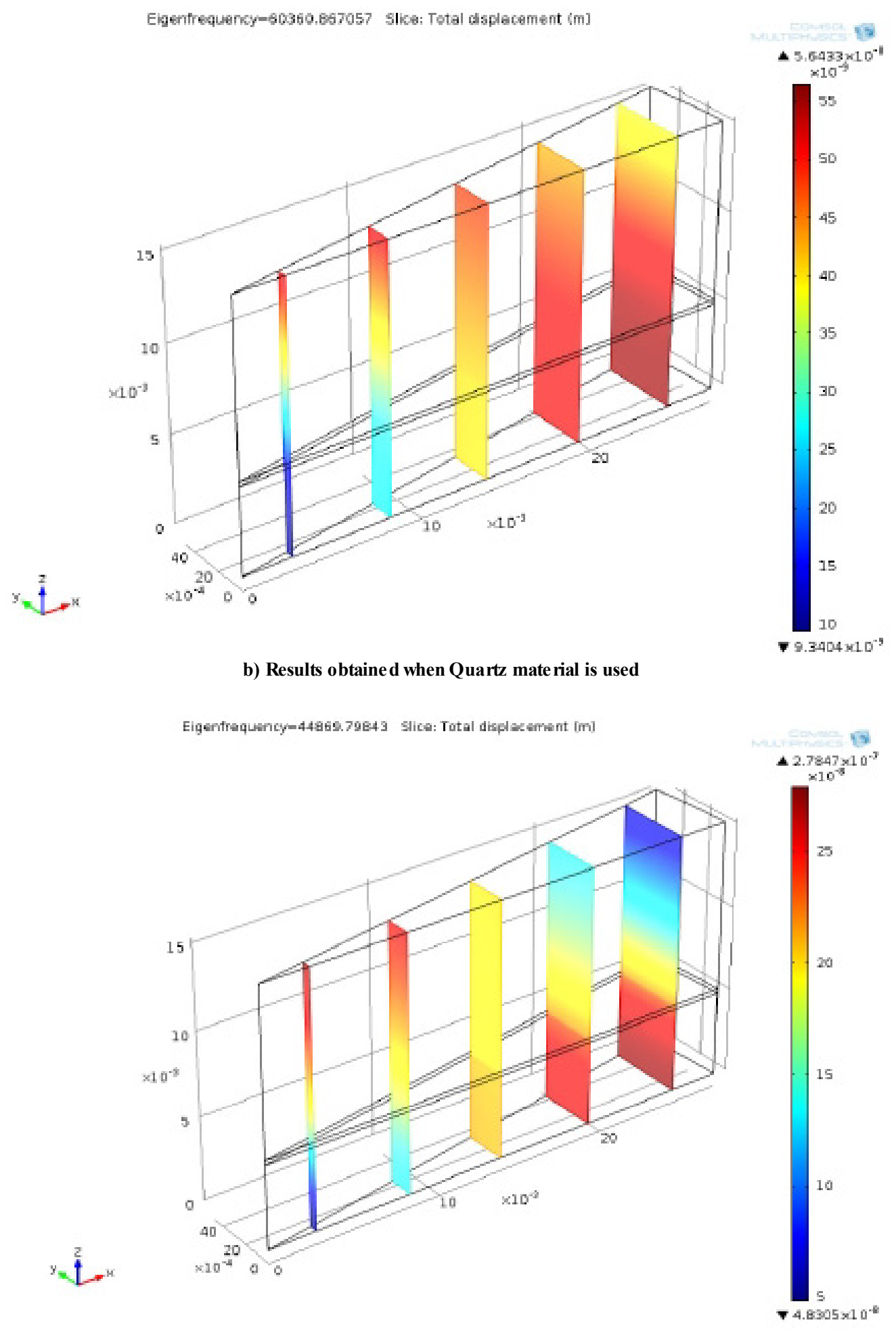

c) Results obtaine $d$ when PZT - 8 material is used

Figure 8. Slices of transducer (3-DP lot group 2)

The first material we considered for analysis was Nepec 6 where the minimum and maximum deformations are $-1.7719 \times 10^{-8}$ and $2.2744 \times 10^{-7}$ respectively for the eigenfrequency 43196.272163 , which is shown in Fig. 7a. But when Quartz was used the deformation values for minimum and maximum are $5.066 \times 10^{-10}$ and $-52589 \times 10^{-8}$ respectively, which can be observed in Fig. 7b. When Pzt-8 is subjected to test for computation of eigen modes, the deformation can be noted from Fig. 9c which shows the minimu $\mathrm{m}$ to maximum range i.e., fro $\mathrm{m}-1.3853 \times 10^{-8}$ and $2.5187 \times 10^{-7}$ for the eigenfrequency 44869.06253 .

After the application of frequency swept the minimum and maximum values of deformation for Nepec 6 are in the range 
of 0 to $9.2582 \times 10^{-10}$, which was shown in Fig. 9a. Whereas when Quartz was taken into consideration the minimum and maximu values of deformation are $-5.19 \times 10^{-19}$ and $3.5214 \times 10^{-19}$, which can be observed in Fig. 9b. On the other hand Fig. $9 \mathrm{c}$ corresponds to Pzt- 8 results, in which the deformation values for minimu $\mathrm{m}$ and maximum are in the range of-2.4778 $10^{-8}$ and 0 .

$$
\text { freq }(44)=1.06 e 5
$$

Irface: Displacement field, $\mathrm{Z}$ component (m) Surface Deformation: Displacement field

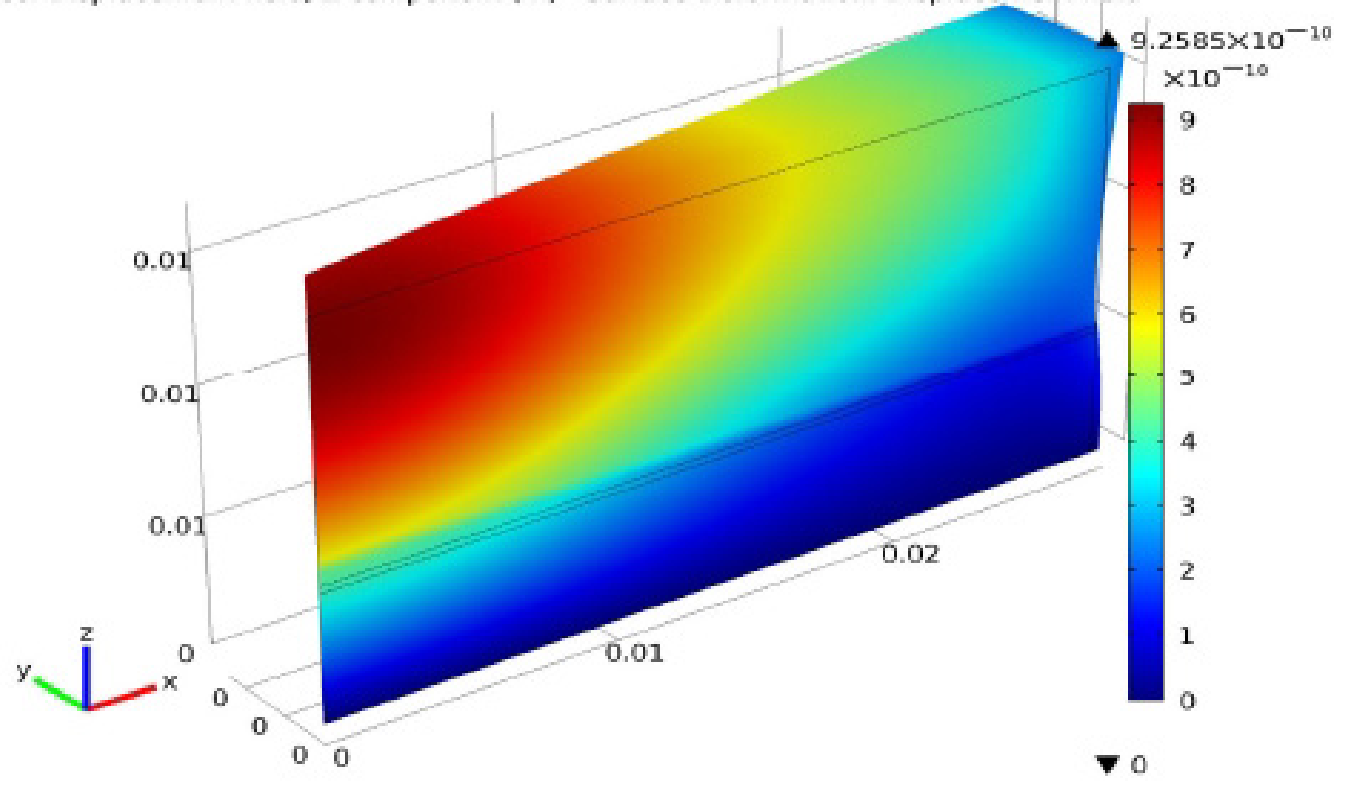

a) Results obtained when Nepec 6 mate rial is used

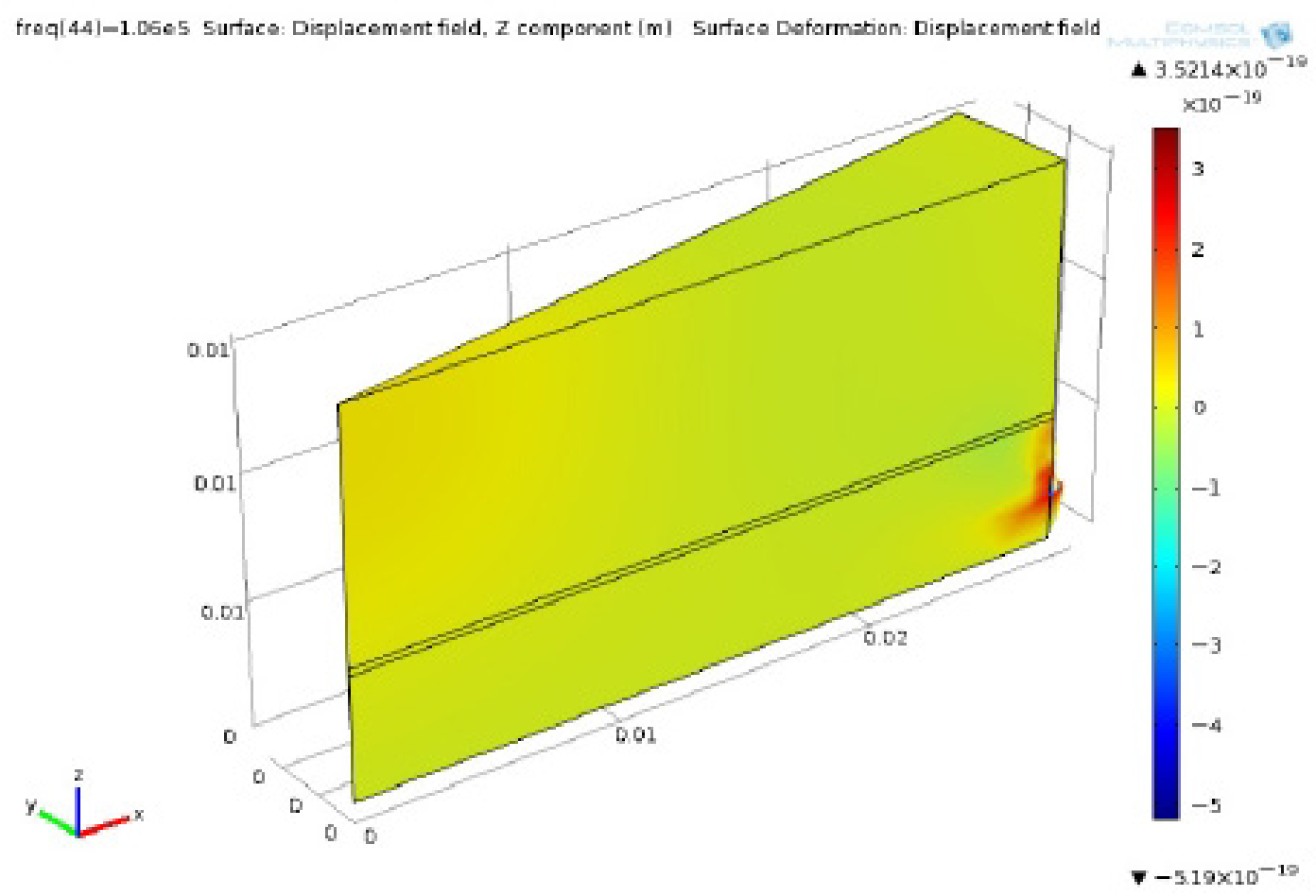

b) Results obtained when Quartz mate rial is used 


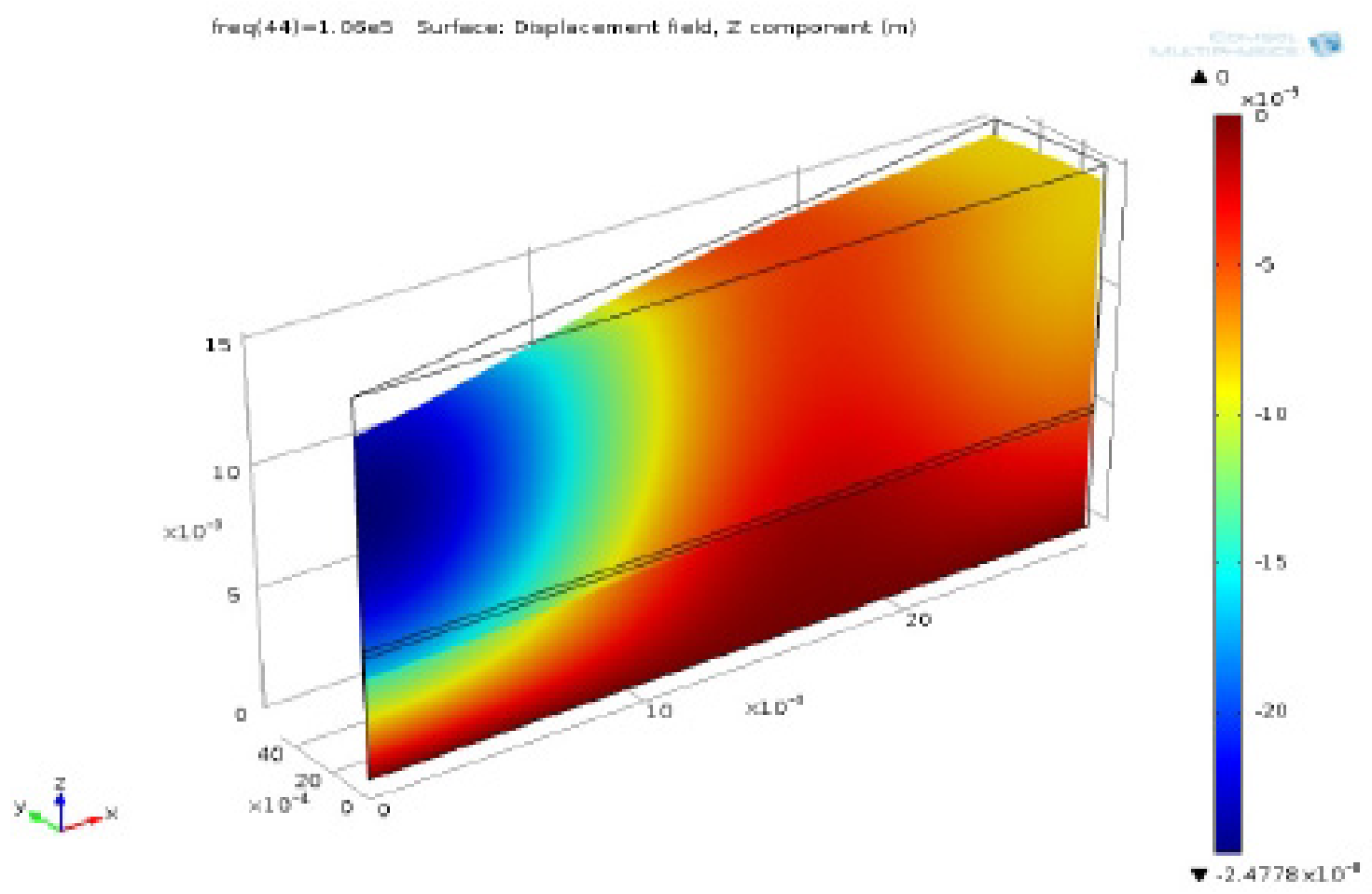

c) Results obtained when PZT - 8 material is use d.

Figure 9. Deformation for the frequency Swept (3-D plot group 3)

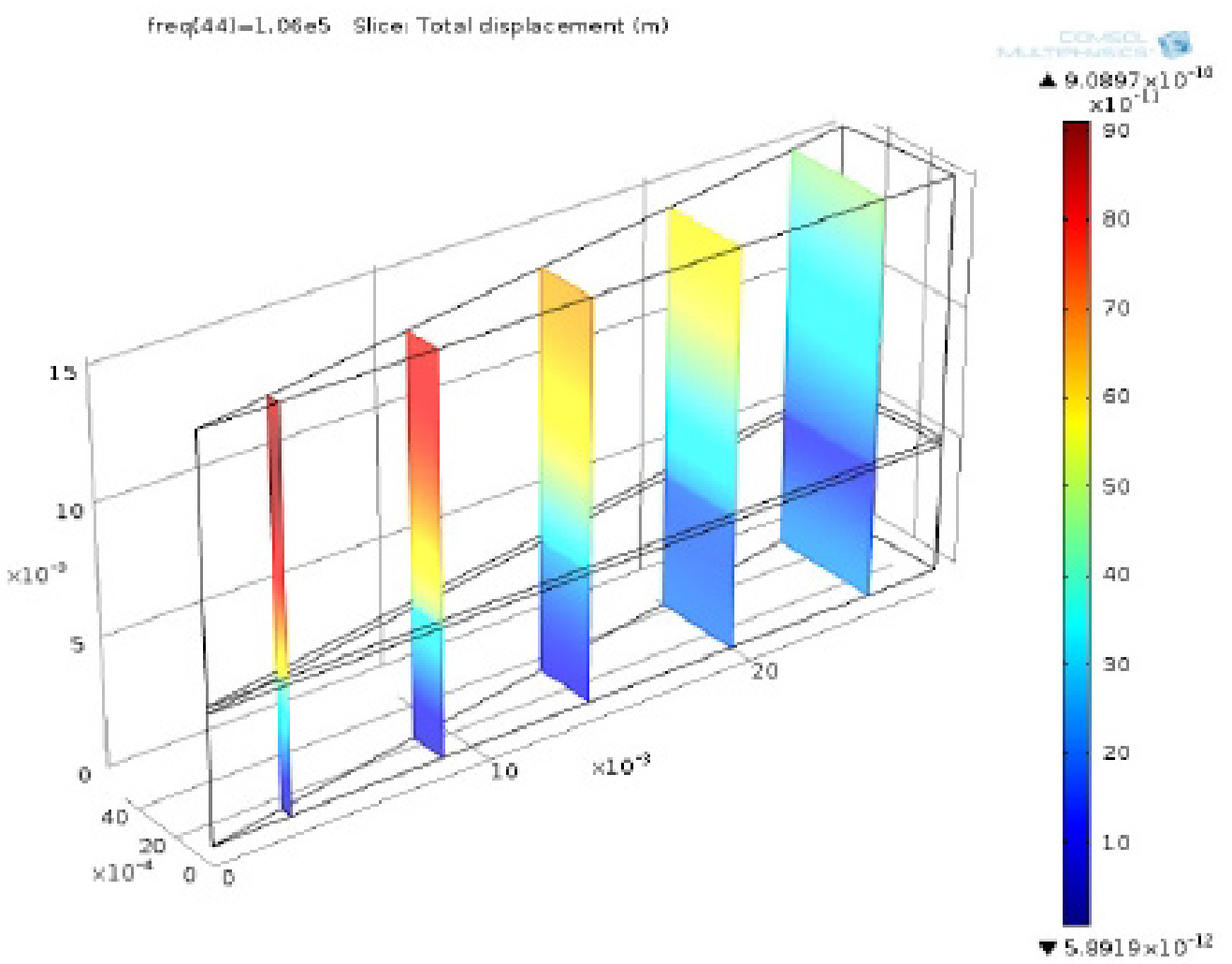

a) Resul ts obtained when Nepec 6 mate rial is used. 


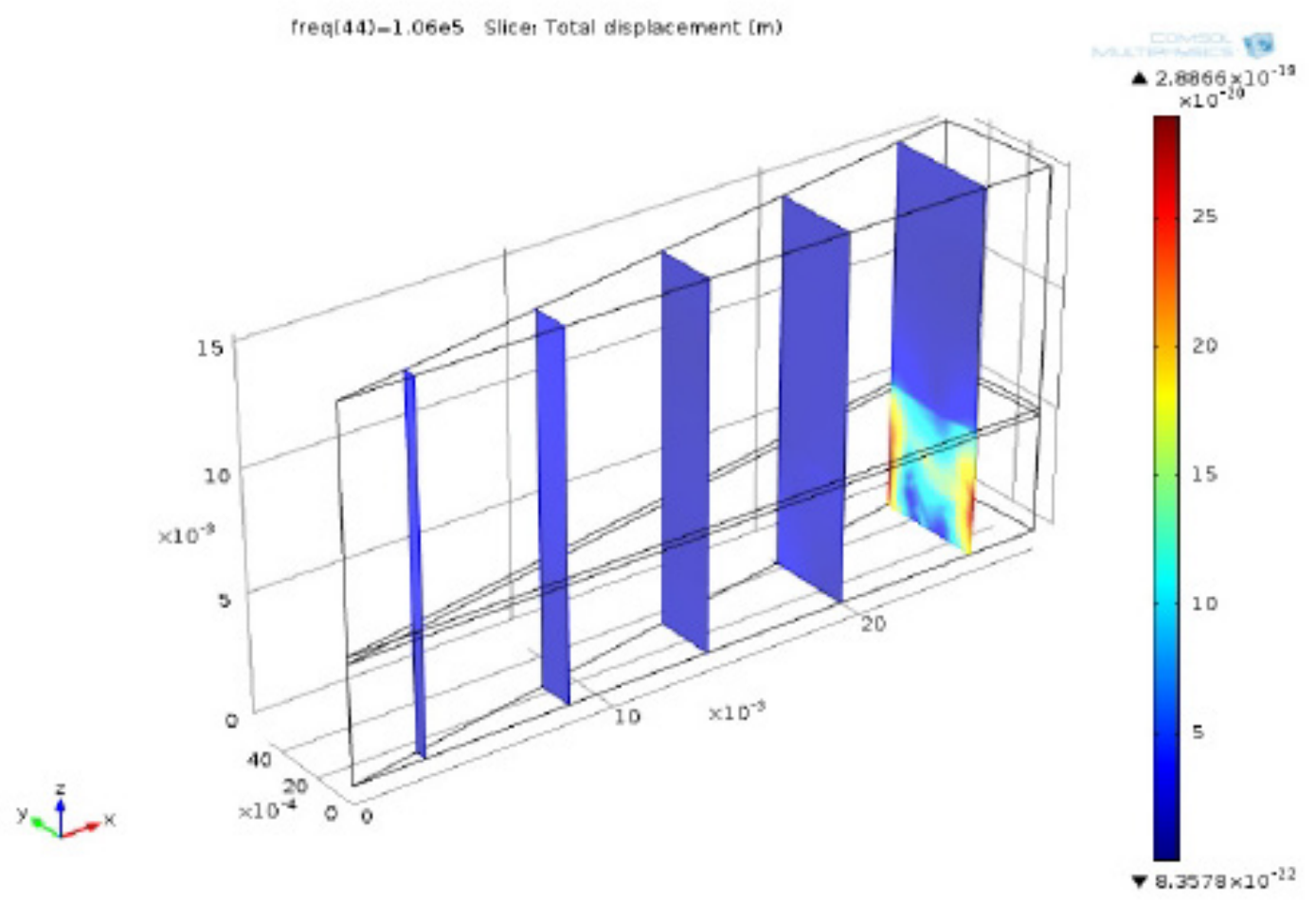

b) Results obtained when Quartz mate rial is used.

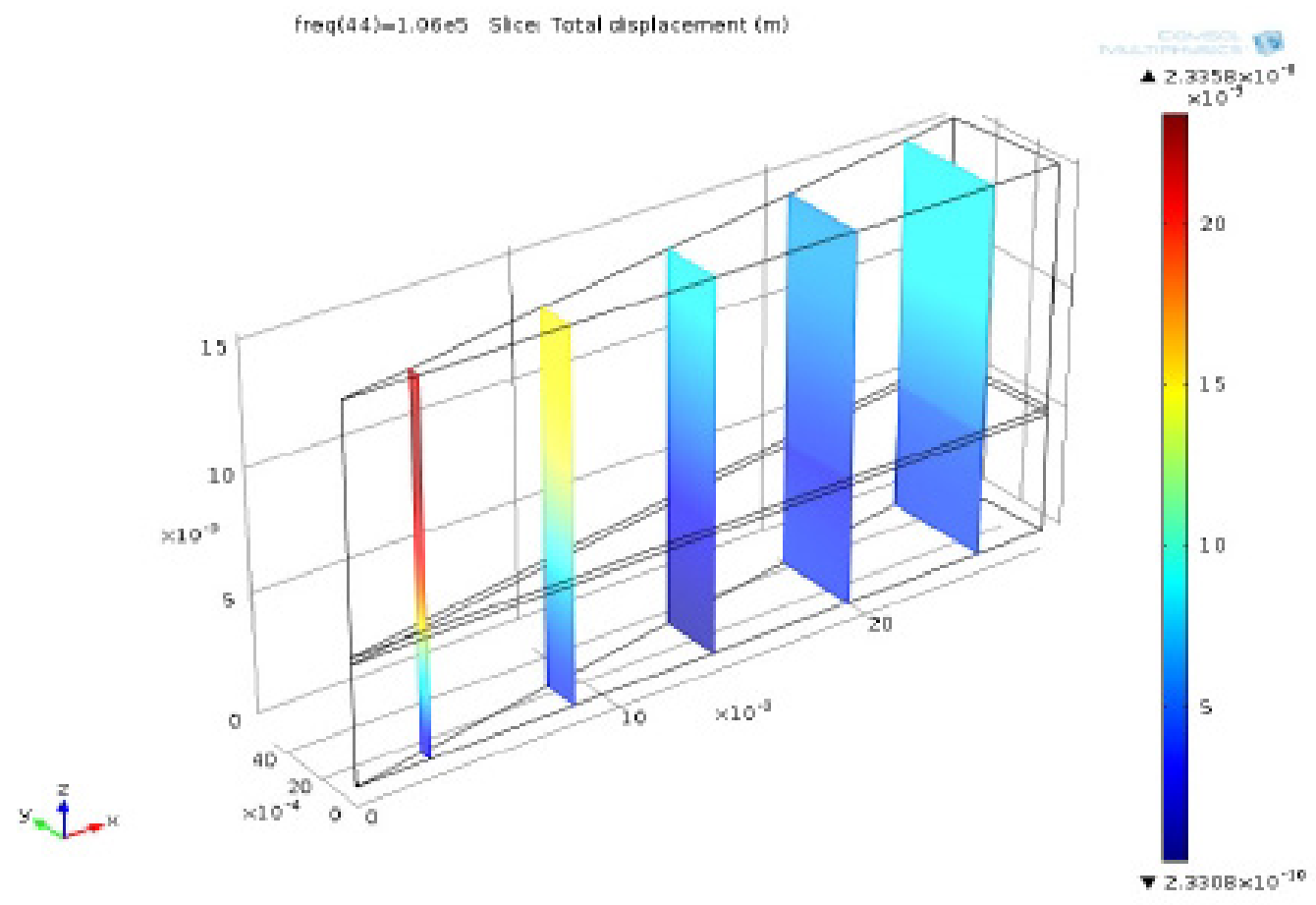

c) Results obtained when PZT - 8 material is used.

Figure 10. Slices for frequency swept (3-D plot group 4)

The minimum and maximum total displacements values in meters for the model when Nepec 6 material is used are $4.4729 \times 10^{-8}$ and $2.6688 \times 10^{-7}$ respectively. Whereas for the frequency swept of freq $(44)=1.60 \mathrm{e} 5$, the displacement values are $5.8919 \times 10^{-12}$ and $9.0897 \times 10^{-10}$, which are shown in the form of the slices and can be observed from Fig. 8a and 10 a respectively. When Quartz material is used, the range is fro $\mathrm{m} 9.3404 \times 10^{-9}$ to $5.6433 \times 10^{-8}$ and after frequency is applied the displacement values are $8.3578 \times 10^{-22}$ to $2.8866 \times 10^{-19}$, as shown in Fig. $8 \mathrm{~b}$ and $10 \mathrm{~b}$ respectively. On the other hand, from the 
Fig. $8 \mathrm{c}$ and $11 \mathrm{c}$, Pzt- 8 resulted in the displacement range from $4.8305 \times 10^{-8}$ to $2.7847 \times 10-7$, whereas after application of frequency, the minimu m to maximu m displacement range is from $2.3308 \times 10^{-10}$ to $2.3358 \times 10^{-8}$ respectively.

When input susceptance is calculated as an function of excitation frequency, the maximum susceptance value is 0.005 Siemens with minimum value of -0.0035 Siemens for the Nepec 6 material, which is shown in Fig. $11 \mathrm{a}$. Whereas Quartz material resulted for the maximum and minimum in the values in the range of $6 \times 10^{6} \mathrm{w}$ ith the minimum of $0.2 \times 10^{5}$ that are shown in Fig. 11 b. On the other hand the susceptance value is 0.015 Siemens for the Pzt- 8 material, which is shown in Fig. 11 c.

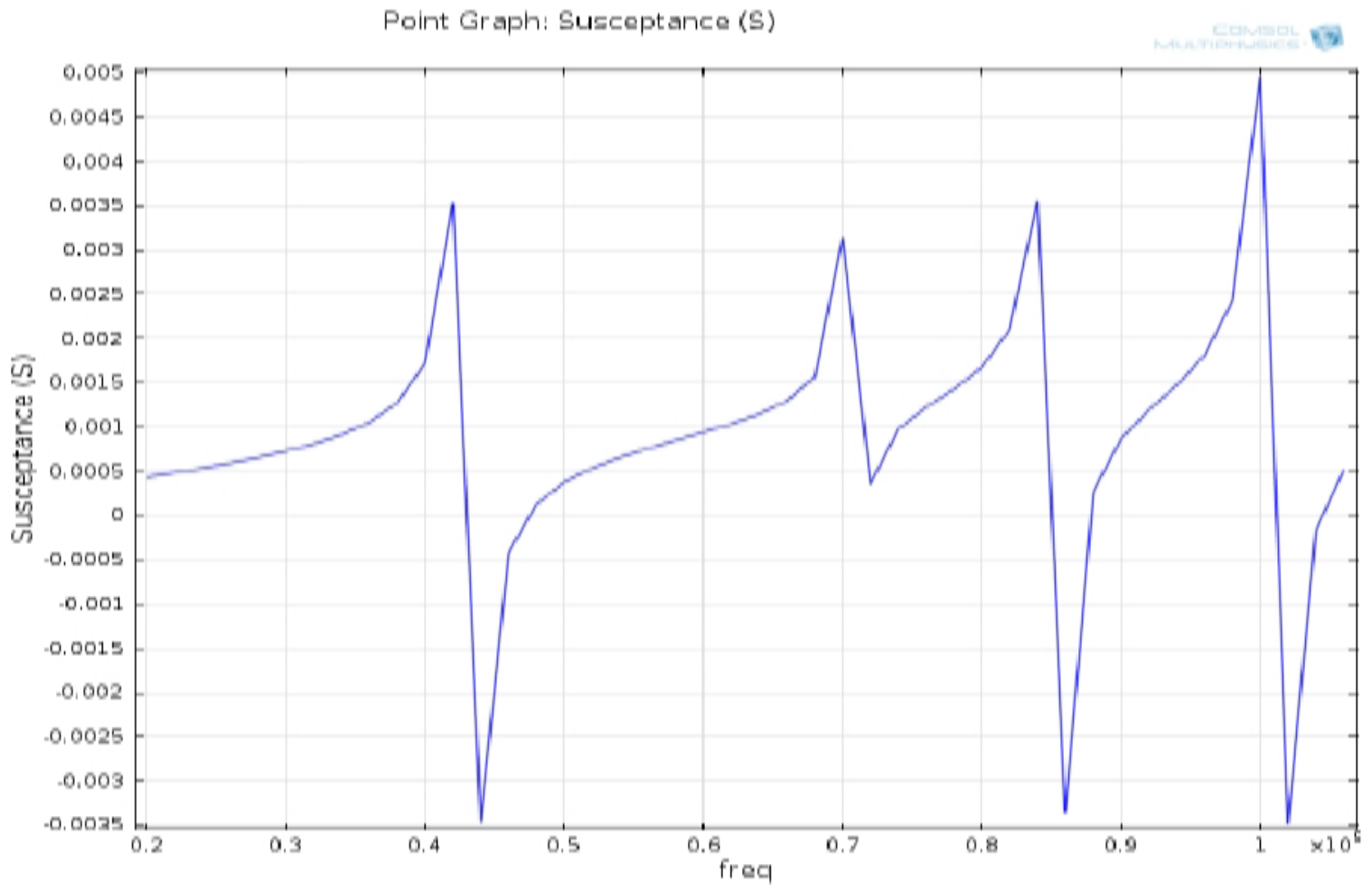

a) Resul ts obtained when NEPEC 6 mate rial is used.

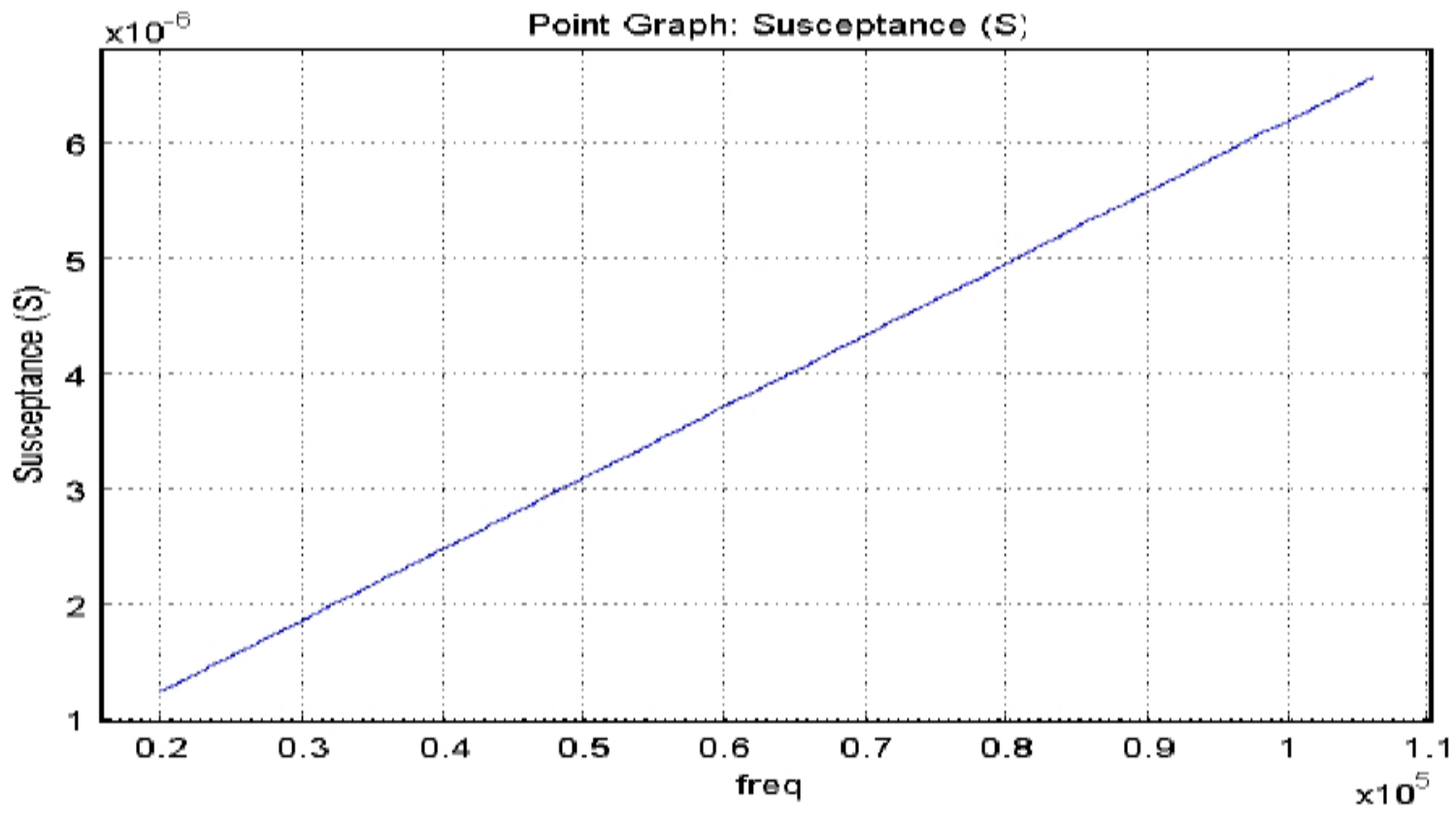

b) Results obtaine d when Quartz mate rial is used. 


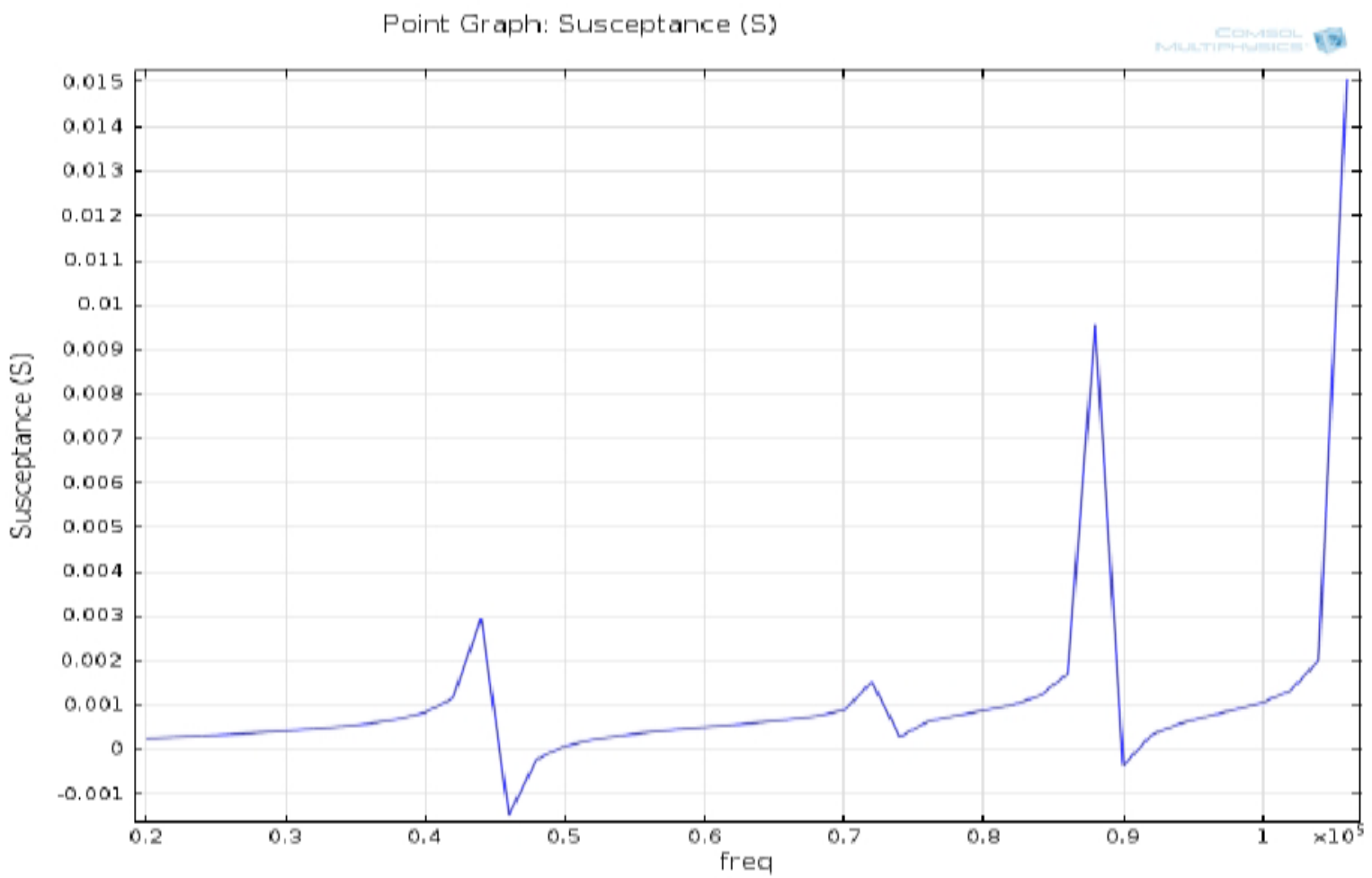

c) Results obtained when PZT - 8 material is use d.

Figure 11. Input susceptance as a function of excitation frequency

\section{Conclusions}

MEMS composite ultrasonic transducer was designed and simulated using COMSOL Multiphysics version $4.2 \mathrm{a}$ with three different piezoe lectric materials. We have analysed the susceptance results as a function of excitation frequency for the four lowest eigenfrequencies of the structure. From the analys is of these results, the proposed composite transducer used PZT- 8 material was exhibiting better value of susceptance rather than other materials. Thus it allowed us to conclude that the PZT- 8 u ltras onic transducer exhibits better sensitivity which can find many non destructive testing applications.

\section{ACKNOWLEDGEMENTS}

The authors would like to thank NPMASS for the establishment of National MEMS Design Centre (NMDC) at Lakireddy Bali Reddy Autonomous Engineering College. The authors would also like to thank the Management $\&$ the Director of LBRCE, for providing us the necessary facilities.

\section{REFERENCES}

[1] Mohammad Gad-El-Hak "Micro electro mechanical systems" (University of Notre Dame) (2002)
[2] Ioan Raicu "MEMS Technology Overview and limitations" (2004)

[3] Trimmer, W S N T, Sensors Actuators, New York, 97, pp. 96-116 (1989)

[4] S Rao Karumuri, Advances in Applied Science Research, 2, 570 ( 2011)

[5] S Rao Karumuri, Archives of Physics Research, 2, 158 (2011)

[6] S Rao Karumuri, IJASETR, 1(1), (2012)

[7] S Rao Karumuri, IJASETR, 1(2), (2012)

[8] Wang Y, Lee C and Ming Chiang, Sensors Vol.7, 2389 (2007)

[9] Waldner, Jean- Baptiste (2008) "Nanocomputers and Swam Intelligence". London: ISTE John Wiley \& Sons. p. 205. ISBN 1848210094.

[10] Tao Li, Jan Ma and Adrian F. Low, "Horn-Type Piezoelectric Ultrasonic Transducer: Modelling and Applications", Advances in Piezoelectric Transducers, Farzad Ebrahimi (Ed.), InTech, ISBN: 978-953-307-931-8, (2011).

[11] W. Sachse and N. N. Hsu, "Ultrasonic transducers for materials testing and their Characterization", in Physical Acoustics-Principles and Methods; W. P. Mason and E. N. Thurston, Eds. New York: Academic Press, XIV, (1979) 277-406.

[12] Y. Kagawa and T. Yamabuchi, "Finite Element Simulation of a Composite Piezoelectric Ultrasonic Transducer", IEEE Transactions on Sonics and Ultrasonics, SU-26, (1979) 81-88. 